\title{
microRNA-497 overexpression decreases proliferation, migration and invasion of human retinoblastoma cells via targeting vascular endothelial growth factor $\mathrm{A}$
}

\author{
JIANJUN LI $^{1}$, YINGHUI ZHANG ${ }^{1}$, XIUCHAO WANG ${ }^{1}$ and RUIBO ZHAO ${ }^{2}$ \\ ${ }^{1}$ Department of Ophthalmology, Xi'an XD Group Hospital, Xi'an, Shaanxi 710077; \\ ${ }^{2}$ Refractive Surgery Center, Xi'an Aier Ancient City Eye Hospital, Xi'an, Shaanxi 710061, P.R. China
}

Received September 7, 2015; Accepted February 28, 2017

DOI: $10.3892 / \mathrm{ol} .2017 .6083$

\begin{abstract}
The expression level and roles of microRNA-497 (miR-497) have been frequently reported in previous studies on cancer. However, its expression, function and associated molecular mechanisms in retinoblastoma remain unknown. In the present study, miR-497 expression levels in human retinoblastoma tissues, normal retinal tissues and retinoblastoma cell lines were determined using reverse transcription-quantitative polymerase chain reaction. In addition, a Cell Counting Kit-8 assay, cell migration assay, cell invasion assay, western blot analysis and Dual-Luciferase reporter assay were used to explore the expression, functions and molecular mechanisms of miR-497 in human retinoblastoma. It was demonstrated that miR-497 was significantly downregulated in retinoblastoma tissues and cell lines compared with normal retinal tissues. Ectopic expression of miR-497 decreased the proliferation, migration and invasion of retinoblastoma cells. Furthermore, VEGFA was verified as a potential direct target of miR-497 in vitro. Taken together, the results indicate that miR-497 functions as a tumor suppressor in the carcinogenesis and progression of retinoblastoma via targeting VEGFA. miR-497 should be investigated as a potential therapeutic target for the treatment of retinoblastoma.
\end{abstract}

\section{Introduction}

Retinoblastoma, the most common primary malignancy in the retina, usually occurs in childhood and accounts for $2-4 \%$ of all childhood malignancies. The morbidity rate is $\sim 1: 15,000-1: 20,000$ in children $<5$ years of age $(1,2)$. In 2015 , it was estimated that there were 2,580 new cases in the United

Correspondence to: Professor Ruibo Zhao, Refractive Surgery Center, Xi'an Aier Ancient City Eye Hospital, 59 West Road, Xi'an, Shaanxi 710061, P.R. China

E-mail: zhaoruibo_8896@163.com

Key words: microRNA-497, retinoblastoma, vascular endothelial growth factor A, targeted therapy
States (3). Various factors are involved in the carcinogenesis and development of retinoblastoma, including genetic and epigenetic alterations to oncogenes and tumor suppressor genes, and a large number of these have previously been demonstrated to regulate cell growth, the cell cycle and apoptosis $(4,5)$. In developed countries, $>95 \%$ of patients with retinoblastoma have a good prognosis. However, in patients with advanced disease, the prognosis remains unsatisfactory due to metastasis to distant organs $(6,7)$. Currently, the main therapeutic strategies for patients with retinoblastoma are surgery (removal of the eyes), thermotherapy, cryotherapy, chemotherapy (systemic and local delivery) and radiotherapy (8). Despite advances in the development of therapeutic strategies for patients with retinoblastoma, a proportion of retinoblastoma cases respond only transiently to these treatments (9). Given this, it is necessary to further explore the molecular mechanisms underlying the initiation and progression of retinoblastoma and to develop effective treatments, including molecular targeted therapy, a novel potential option for individualized therapy.

Accumulating evidence suggests that abnormal expression levels of a variety of microRNAs (miRNAs) are often present in various types of human cancer, including retinoblastoma, indicating the potential functions of miRNAs in carcinogenesis and cancer progression (10-12). miRNAs, which are a class of single-stranded, short ( 23 bases in length) and non-protein-coding RNAs, act as negative regulators of their target mRNAs by binding to the $3^{\prime}$ untranslated region (UTR) of the mRNA, resulting in target degradation or translational repression $(5,13)$. An increasing number of studies have revealed that miRNAs are involved in a wide variety of physiological and pathological processes, including cell proliferation, the cell cycle, apoptosis, differentiation, angiogenesis, migration, invasion and metastasis $(14,15)$. miRNAs may act as oncogenes or tumor suppressors in cancer, depending on their target mRNA (16). miRNAs that are downregulated in cancer normally act as tumor suppressors, whereas upregulated miRNAs usually act as oncogenes (17). Therefore, the identification of target mRNAs of miRNAs is important in order to further understand the roles of miRNAs in cancer initiation and progression. Due to the regulatory functions of miRNAs in cancer initiation and progression, targeting of miRNAs should be investigated as a novel therapeutic strategy. 
miR-497, a member of the miR-15/16/195/424/497 family, has been demonstrated to be aberrantly expressed in numerous types of cancer (18). However, its expression, function and associated molecular mechanisms in retinoblastoma have not been previously studied. The results of the present study indicate that miR-497 is downregulated in human retinoblastoma tissues and cell lines, and that ectopic expression of miR-497 can suppress proliferation, migration and invasion in retinoblastoma cells via blocking vascular endothelial growth factor A (VEGFA). These findings indicate that miR-497 may be a potential targeted therapy for retinoblastoma.

\section{Materials and methods}

Human retinoblastoma tissue samples. The present study was approved by the Human Subjects Committee of Xi'an XD Group Hospital (Xi'an, China). Written informed consent was also obtained from all patients prior to enrollment in the study. In total, 23 human retinoblastoma tissue samples and 5 normal retinal tissues were used in the present study, and were obtained from patients with retinoblastoma who had undergone surgery in Xi'an XD Group Hospital. These patients had not received thermotherapy, cryotherapy, chemotherapy or radiotherapy prior to surgery. Tissues were immediately snap-frozen in liquid nitrogen and transferred to a $-80^{\circ} \mathrm{C}$ freezer until use.

Cell culture. The Y79 and WERI-Rb-1 human retinoblastoma cell lines were purchased from the American Type Culture Collection (Manassas, VA, USA). Cells were maintained in Gibco RPMI-1640 medium (Thermo Fisher Scientific, Inc., Waltham, MA, USA) supplemented with $10 \%$ Gibco fetal bovine serum (FBS; Thermo Fisher Scientific, Inc.), $100 \mathrm{U} / \mathrm{ml}$ penicillin and $100 \mathrm{mg} / \mathrm{ml}$ streptomycin (Gibco; Thermo Fisher Scientific, Inc.) in humidified atmosphere of $5 \% \mathrm{CO}_{2}$ at $37^{\circ} \mathrm{C}$.

Cell transfection. Mature miR-497 mimics and the negative control miRNA (NC) were synthesized and purchased from Shanghai GenePharma Co., Ltd. (Shanghai, China). To assess the functions of miR-497 in retinoblastoma, miR-497 mimics and NC were transfected into Y79 and WERI-Rb-1 cells. Prior to transfection for $12 \mathrm{~h}$, cells were seeded on 6-well plates at a density of $8 \times 10^{5}$ and cultured in RPMI-1640 without FBS and antibiotics at $37^{\circ} \mathrm{C}$. Cell transfection and co-transfection (with luciferase reporter constructs, as described subsequently) were performed using Lipofectamine ${ }^{\circledR} 2000$ (Invitrogen; Thermo Fisher Scientific, Inc.), according to the manufacturer's instructions. After transfection for 4-6 h, cell culture medium was replaced with RPMI-1640 supplemented with 10\% FBS.

$R N A$ isolation and reverse transcription-quantitative polymerase chain reaction ( $R T-q P C R)$. Total RNA samples from retinoblastoma tissue samples, normal retinal tissues and retinoblastoma cell lines were isolated using TRIzol ${ }^{\circledR}$ reagent (Invitrogen, Thermo Fisher Scientific, Inc.), according to the manufacturer's protocol. Total RNA was reverse transcribed to cDNA using a PrimeScript RT Reagent kit (Takara Biotechnology, Co., Ltd., Dalian, China). RT-qPCR analyses were conducted to detect the expression levels of VEGFA mRNA using Power SYBR-Green PCR Master Mix (Thermo Fisher Scientific, Inc.). The thermocycling conditions of qPCR were as follows: $95^{\circ} \mathrm{C}$ for $10 \mathrm{~min} ; 40$ cycles of $95^{\circ} \mathrm{C}$ for $15 \mathrm{sec}$; and $60^{\circ} \mathrm{C}$ for $1 \mathrm{~min}$. This reaction included $2 \mu 1 \mathrm{cDNA}(200 \mathrm{ng})$, $2 \mu \mathrm{l}$ forward primer and $2 \mu \mathrm{l}$ reverse primer.

miR-497 expression was determined using a SYBR Premix Ex Taq mix (Takara Biotechnology, Co., Ltd.). This stage was performed with cycling conditions as follows: $5 \mathrm{~min}$ at $95^{\circ} \mathrm{C}$; followed by 40 cycles of $95^{\circ} \mathrm{C}$ for $30 \mathrm{sec}$; and $65^{\circ} \mathrm{C}$ for $45 \mathrm{sec}$. An ABI 7500 sequence detection system (Applied Biosystems; Thermo Fisher Scientific, Inc.) was used for thermal cycling. This reaction included $2 \mu \mathrm{l}$ cDNA (200 ng), $2 \mu \mathrm{l}$ forward primer and $2 \mu \mathrm{l}$ reverse primer. The primer sequences used for qPCR were: miR-497 forward, 5'-CCAGTCTCAGGGTCCGAG GTATTC-3' and reverse, 5'-GTGCAGGGTCCGAGGT-3'; U6 forward, 5'-CGCTTCGGCAGCACATATACTA-3' and reverse, 5'-GCGAGCACAGAATTAATACGAC-3'; VEGFA forward, 5'-ACTTTCTGCTGTCTTGGGTG-3' and reverse, 5'-CTGCAT GGTGATGTTGGACT-3'; and GAPDH forward, 5'-TGGTAT CGTGGAAGGACTCA-3' and reverse, 5'-CCAGTAGAGGCA GGGATGAT-3'. Relative expression levels were determined normalized to the expression level of GAPDH or U6. Relative expression levels were evaluated using the $2^{-\Delta \Delta C q}$ method (19). All samples were analyzed in triplicate.

Cell Counting Kit-8 assay. Following a 24-h transfection with miR-497 or NC, transfected cells were collected and resuspended in culture medium, and 3,000 transfected cells in $100 \mu 1$ medium were seeded into each well in 96-well plates. Following various incubation times (24-96 h), cells were treated with CCK-8 reagent (Dojindo Molecular Technologies, Inc., Kumamoto, Japan), according to manufacturer's protocol. In brief, $10 \mu \mathrm{l}$ CCK-8 assay solution was added to each well and incubated in at $37^{\circ} \mathrm{C}$ for $2 \mathrm{~h}$. Absorbance at $450 \mathrm{~nm}$ was detected using the Thermo Scientific Microplate Reader (Thermo Fisher Scientific, Inc.). Each sample was analyzed in triplicate.

Cell migration and invasion assays. The cell migration and invasion assays were performed using Transwell chambers with 8- $\mu \mathrm{m}$ pores (Corning Incorporated, Corning, NY, USA)., The Transwell chambers were coated with Matrigel matrix (BD Biosciences, Franklin Lakes, NJ, USA) for the invasion assay.

Following a 48-h transfection, transfected cells (miR-497 and NC) were collected and resuspended in culture medium without FBS. Transfected cells $\left(1 \times 10^{5}\right)$ in $300 \mu 1$ FBS-free medium were added to the upper chambers, and $500 \mu l$ culture medium containing $20 \%$ FBS was added to the lower chambers. Following incubation at $37^{\circ} \mathrm{C}$ for $24 \mathrm{~h}$, the Transwell chambers were stained with $0.5 \%$ crystal violet (Beyotime Institute of Biotechnology, Haimen, China) for $15 \mathrm{~min}$. Subsequently, non-migrated and non-invaded cells were removed using cotton swabs. Migrated and invaded cells were imaged and counted using an inverted microscope (Olympus Corporation, Tokyo, Japan). Each experiment was repeated at least three times.

Bioinformatic predication. The potential targets of miR-497 were analyzed using miRanda (http://www.microrna.org) and TargetScan (http://www.targetscan.org/). 
Western blot analysis. Following a 72-h transfection, protein was extracted from transfected cells (miR-497 and NC) using RIPA lysis buffer (50 mM Tris- $\mathrm{HCl}, \mathrm{pH} \mathrm{7.4;} \mathrm{1 \%} \mathrm{NP-40;}$ $0.25 \%$ Na-deoxycholate; $150 \mathrm{mM} \mathrm{NaCl} ; 1 \mathrm{mM}$ EDTA; $1 \mathrm{mM}$ phenylmethylsulfonyl fluoride; $1 \mu \mathrm{g} / \mathrm{ml}$ each of aprotinin, leupeptin, pepstatin; $1 \mathrm{mM} \mathrm{Na} \mathrm{VO}_{4} ; 1 \mathrm{mM} \mathrm{NaF}$ ). Protein concentration was detected using a bicinchoninic acid assay kit (Beyotime Institute of Biotechnology). Subsequently, equal amounts of protein were separated by $10 \%$ SDS-PAGE (Bioworld Technology, Inc., St. Louis Park, MN, USA) and electro-transferred to polyvinylidene difluoride membranes (Beyotime Institute of Biotechnology). The membranes were blocked with $5 \%$ non-fat milk for $1 \mathrm{~h}$ at room temperature, and then incubated at $4{ }^{\circ} \mathrm{C}$ overnight with a mouse anti-human VEGFA monoclonal primary antibody (dilution, 1:1,000; cat no. ab155944; Abcam, Tokyo, Japan) and mouse anti-human $\beta$-actin monoclonal primary antibody (dilution, 1:1000; cat no. sc-130,065; Santa Cruz Biotechnology, Inc., Dallas, TX, USA). Subsequently, the membranes were incubated with a corresponding horseradish peroxidase-conjugated secondary antibody (dilution, 1:5,000; cat no. sc-2005; Santa Cruz Biotechnology, Inc.) in TBS with Tween-20 (Beyotime Institute of Biotechnology). The bands were detected using an enhanced chemiluminescence solution (Pierce; Thermo Fisher Scientific, Inc.) and imaged using the FluorChem imaging system (Alpha Innotech, San Leandro, CA, USA). Protein expression was quantified using Quantity One software (Bio-Rad Laboratories, Inc., Hercules, CA, USA). $\beta$-actin was used as the internal control. This assay was repeated three times.

Dual-Luciferase reporter assay. In order to explore whether VEGFA was a direct target of miR-497, a Dual-Luciferase Reporter Assay (Promega Corporation, Madison, WI, USA) was performed. Cells were transfected with miR-497 mimics or NC and co-transfected with pGL3 Luciferase Reporter Vectors (Promega Corporation) containing wild-type (Wt) or mutated (Mut) 3'-UTR sequences of VEGFA (pGL3-VEGFA-3'-UTR-Wt and pGL3-VEGFA-3'-UTR-Mut, respectively). After 48 h, Dual-Luciferase Reporter Assays were performed to detect firefly and Renilla luciferase activities. Renilla luciferase activities were evaluated as an internal control. Each sample was assayed in triplicate.

Statistical analysis. Data are presented as the mean \pm standard deviation of at least three independent experiments, and were statistically analyzed using two-tailed Student's t test or one-way analysis of variance with SPSS 16.0 statistical software (SPSS, Inc., Chicago, IL, USA). Student-Newman-Keuls method was used to compare between two groups in multiple groups. Two-tailed $\mathrm{P}<0.05$ was considered to indicate a statistically significant difference.

\section{Results}

miR-497 expression is downregulated in retinoblastoma tissues and cell lines. RT-qPCR was performed to evaluate miR-497 expression in 23 retinoblastoma tissues and 5 normal retinal tissues. As shown in Fig. 1A, miR-497 was significantly downregulated in retinoblastoma tissues compared with
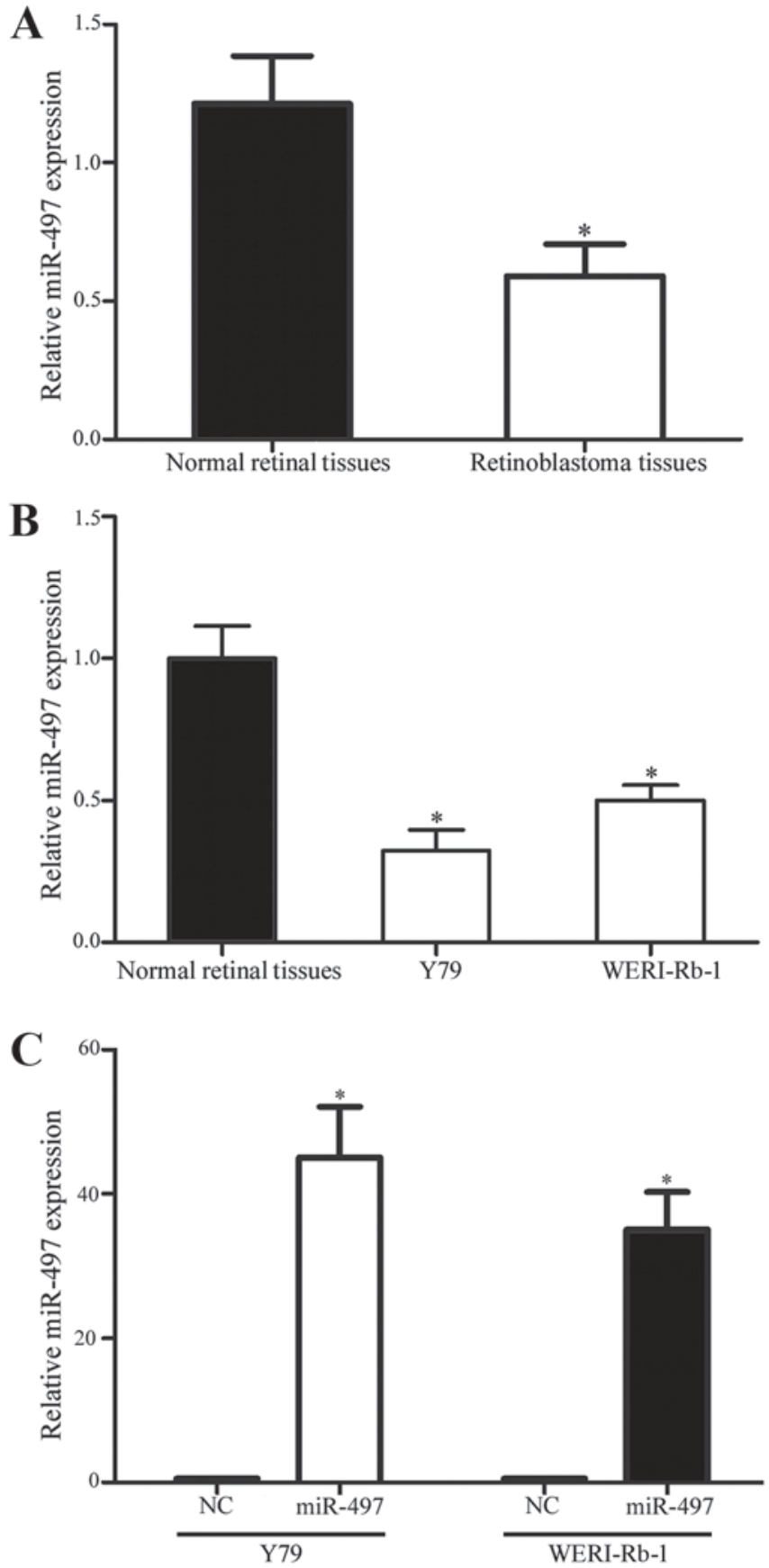

Figure 1. miR-497 expression level in retinoblastoma tissues and cell lines was determined by reverse transcription-quantitative polymerase chain reaction. (A) miR-497 was significantly downregulated in retinoblastoma tissues compared with normal retinal tissues. (B) The expression level of miR-497 was decreased in Y79 and WERI-Rb-1 retinoblastoma cell lines, in comparison with normal retinal tissues. (C) Following transfection with miR-497 mimics, miR-497 was significantly upregulated in normal retinal tissues or NC. ${ }^{*} \mathrm{P}<0.01$. miR, microRNA; NC, negative control.

in normal retinal tissues $(\mathrm{P}<0.05)$. In addition, the present study examined the expression levels of miR-497 in Y79 and WERI-Rb-1 retinoblastoma cell lines. The results revealed that miR-497 was also downregulated in Y79 and WERI-Rb-1 cell lines in comparison with 5 normal retinal tissues $(\mathrm{P}<0.05$; Fig. 1B). Furthermore, the expression levels of miR-497 in Y79 and WERI-Rb-1 cells following transfection with miR-497 mimics or NC were evaluated. As shown in Fig. 1C, 
Y79

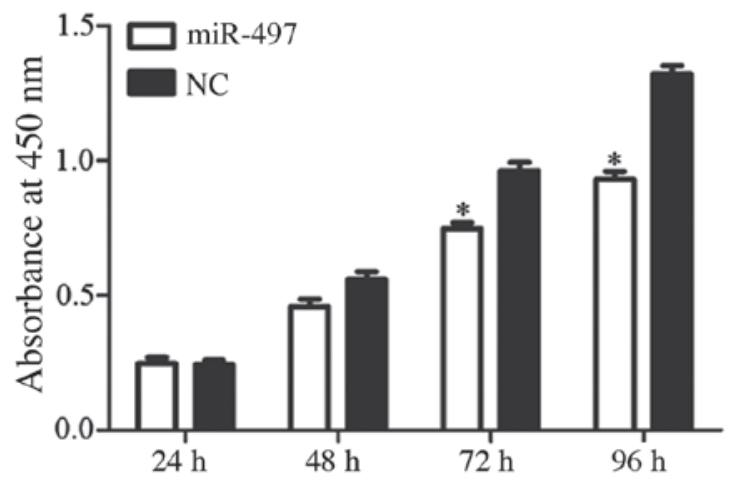

WERI-Rb-1

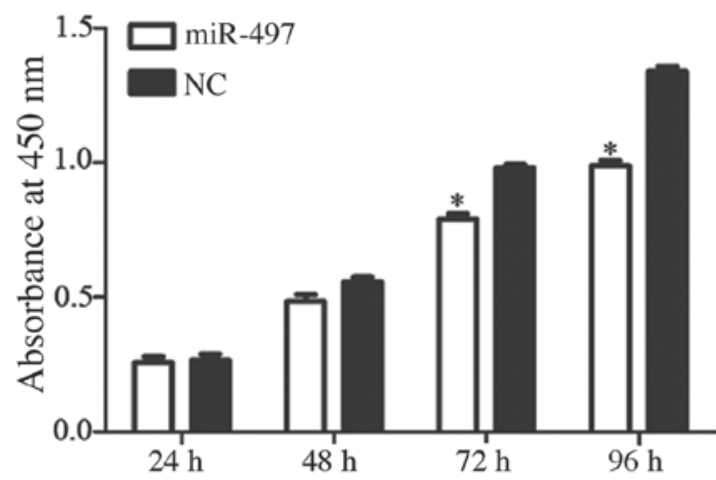

Figure 2. Cell proliferation was determined by Cell Counting Kit-8 assay. miR-497 suppressed cell proliferation in Y79 and WERI-Rb-1 cells. " $\mathrm{P}<0.05$ vs. respective NC. miR, microRNA; NC, negative control.

A

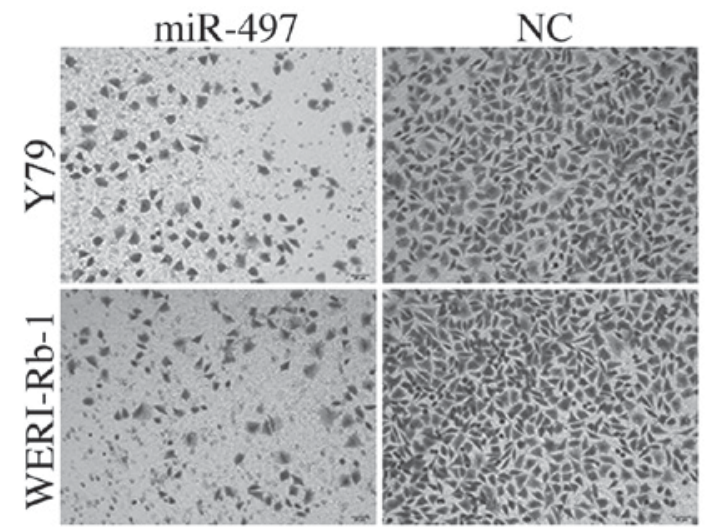

B

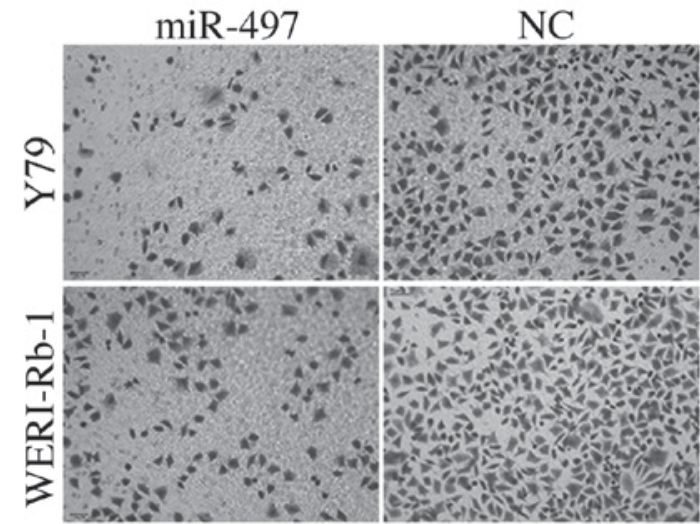

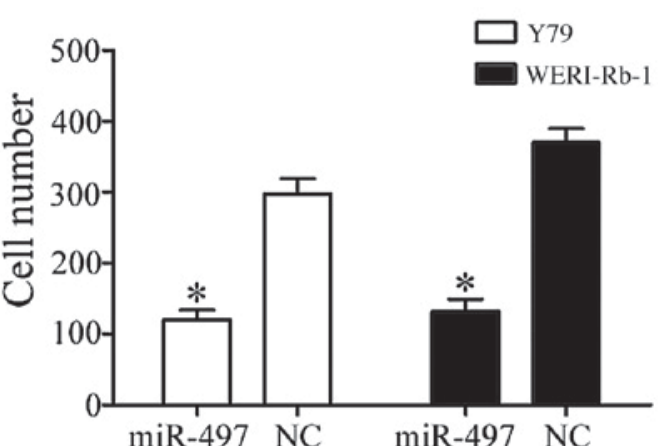

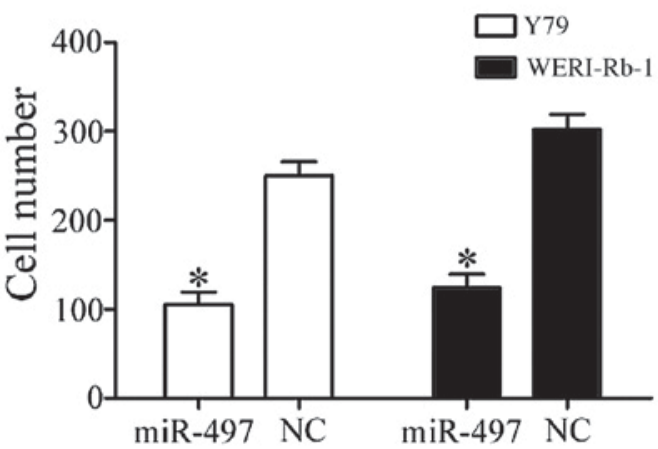

Figure 3. Cell migration and invasion assay was determined using Transwell chambers. Transfection with miR-497 mimics decreased (A) migration and (B) invasion in $\mathrm{Y} 79$ and WERI-Rb-1 cells. ${ }^{*} \mathrm{P}<0.05$ vs. respective NC. miR, microRNA; NC, negative control.

miR-497 was upregulated in the miR-497 mimic transfectants compared with the NC transfectants $(\mathrm{P}<0.05)$.

miR-497 suppresses cell proliferation in Y79 and WERI-Rb-I cells. A CCK-8 assay was performed to assess the role of miR-497 in retinoblastoma cell proliferation. As presented in Fig. 2, restoration of miR-497 via transfection with mimics significantly suppressed Y79 and WERI-Rb-1 cell proliferation after 72 and $96 \mathrm{~h}(\mathrm{P}<0.05)$. After $96 \mathrm{~h}$, cell proliferation was decreased by $30.48 \pm 5.7 \%$ in miR-497-transfected Y79 cells and $26.21 \pm 4.5 \%$ in miR-497-transfected WERI-Rb-1 cells compared with the NC-transfected cells $(\mathrm{P}<0.05)$.
miR-497 suppresses cell migration and invasion in Y79 and WERI-Rb-1 cells. To investigate the effect of miR-497 on cell migration, Y79 and WERI-Rb-1 cells transfected with miR-497 mimics or NC were seeded into Transwell chambers. Using a Transwell chamber coated with Matrigel matrix, the effect of miR-497 on cell invasion was also investigated. As presented in Fig. 3, in the two cell lines, the percentages of migrated and invaded cells were decreased in cells transfected with miR-497 compared with cells transfected with $\mathrm{NC}($ all $\mathrm{P}<0.05)$.

VEGFA is a potential direct target gene of miR-497 in vitro. Accumulating studies have suggested that miRNAs exert 
A Position 276-283 of VEGFA 3' UTR hsa-miR-497

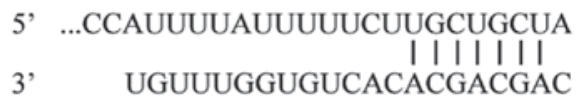

B

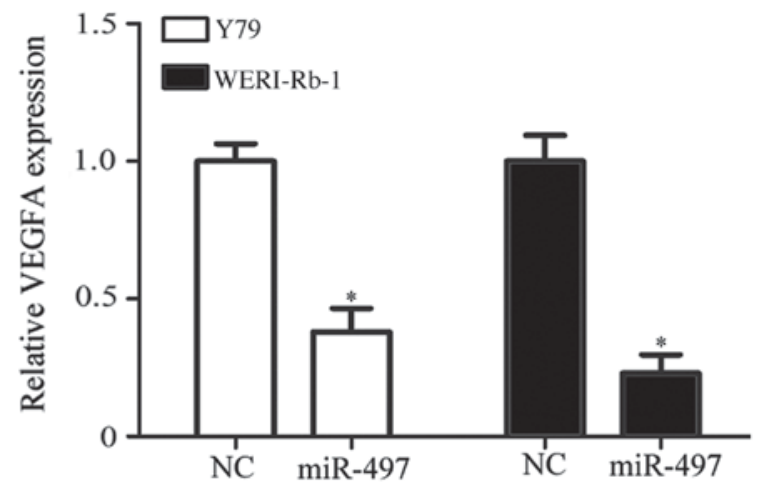

C

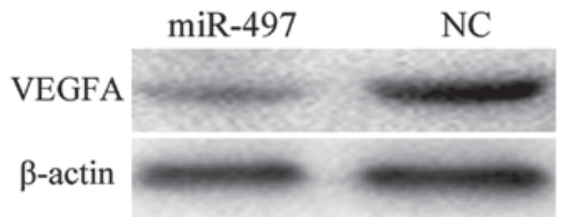

\section{D}
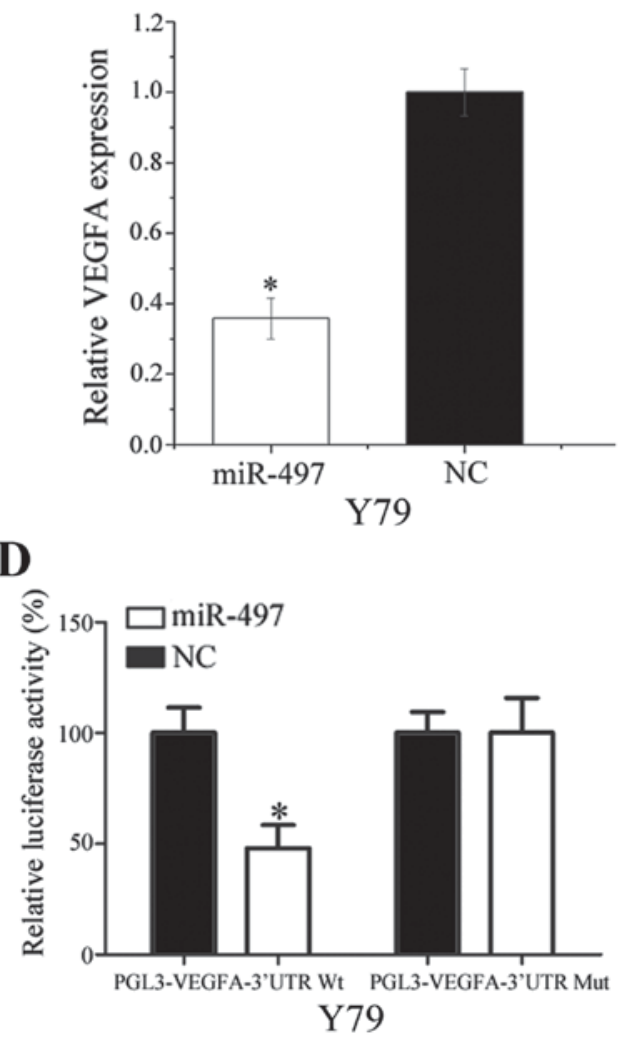
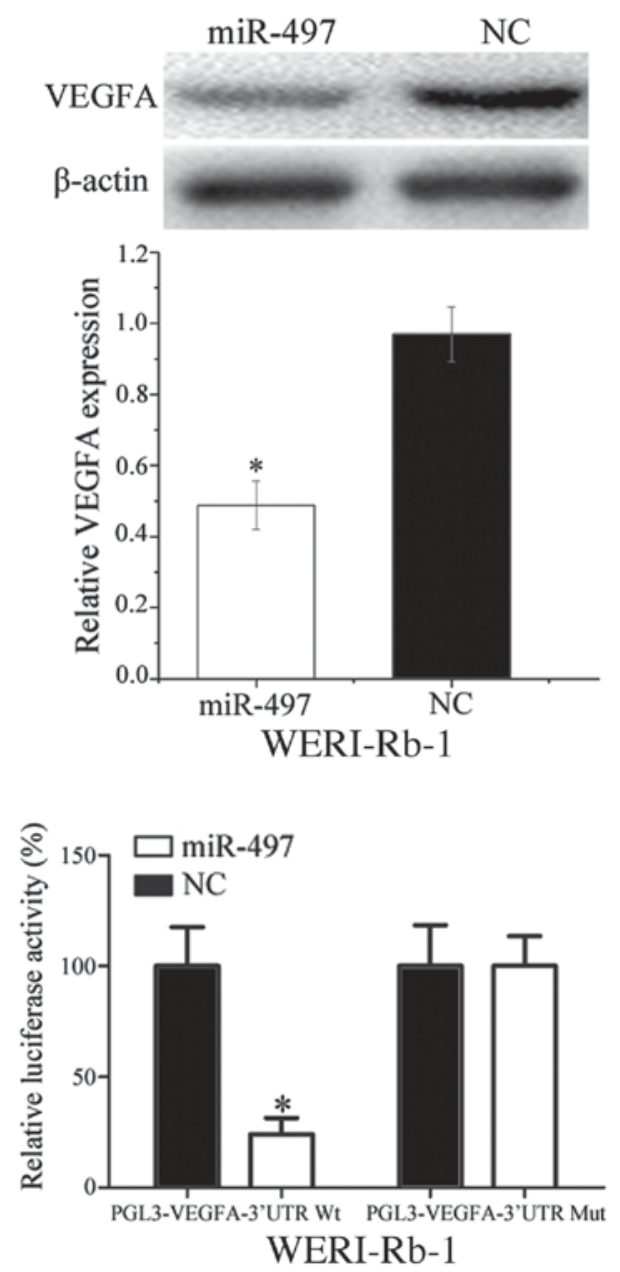

Figure 4. VEGFA is a direct target of miR-497 in vitro. (A) miRanda and TargetScan predicted that the 3'-UTR of VEGFA contains a complementary site for the seed region of miR-497. (B) Upregulation of miR-497 decreased the mRNA expression level of VEGFA. (C) Forced expression of miR-497 significantly decreased VEGFA expression at the protein level. (D) Dual-Luciferase reporter assay revealed that miR-497 significantly inhibited the luciferase activity of the PGL3-VEGFA-3'-UTR-Wt but not PGL3-VEGFA-3'-UTR-Mut in Y79 and WERI-Rb-1 cells. * P<0.05 vs. respective NC. VEGFA, vascular endothelial growth factor A; miR, microRNA; UTR, untranslated region; Wt, wildtype; Mut, mutant.

their functions by directly regulating target mRNA expression levels (20). Thus, in order to identify the target gene of miR-497, miRanda (http://www.microrna.org) and TargetScan (http://www.targetscan.org/) were used. As presented in Fig. 4A, VEGFA was identified as a potential direct target of miR-497; the analysis revealed that position 276-283 of the VEGFA 3'-UTR comprised a region matching the miR-497 seed sequence.
To investigate the effect of miR-497 on VEGFA expression, miR-497 mimics were transfected into Y79 and WERI-Rb-1 cells. The results demonstrated that forced expression of miR-497 significantly decreased VEGFA expression at the mRNA and protein levels (Fig. 4B and $\mathrm{C}$; $\mathrm{P}<0.05$ ).

To confirm that VEGFA was a direct target of miR-497, Y79 and WERI-Rb-1 cells were co-transfected with miR-497 
mimics or NC, and PGL3-VEGFA-3'-UTR-Wt or PGL3-VEGFA-3'-UTR-Mut. It was revealed that miR-497 mimics suppressed the luciferase activity of PGL3-VEGFA-3'-UTR-Wt but not PGL3-VEGFA-3'-UTR-Mut in Y79 and WERI-Rb-1 cells (Fig. 4D; P<0.05). Taken together, these results suggest that VEGFA is directly targeted by miR-497 in vitro.

\section{Discussion}

miR-497, a member of miR-15/16/195/424/497 family, is located on chromosome 17p13.1 (21). The loss or deletion of chromosome $17 \mathrm{p} 13.1$ has been demonstrated in various types of cancer, indicating that miR-497 may be downregulated in cancer due to genomic DNA loss or deletion (22-24). An increasing number of previous studies have demonstrated that the expression level of miR-497 is downregulated in numerous cancer types, including renal cancer (25), pancreatic cancer (26), hepatocellular carcinoma (27), endometrial cancer (28), nasopharyngeal carcinoma (29), and breast (30), colorectal (21), gastric (31) and prostate cancer (32). In renal cancer, miR-497 was shown to be significantly downregulated, and the low miR-497 expression level was associated with tumor stage, histological grade and lymph node metastases (25). In pancreatic cancer, the expression level of miR-497 was significantly decreased in comparison with adjacent non-tumorous tissues. Furthermore, downregulation of miR-497 was an independent adverse prognostic factor for pancreatic cancer and was recommended for investigation as a prognostic marker (26). Guo et al (31) revealed that miR-497 was also downregulated in the plasma of bladder cancer patients compared with healthy patients, which indicated that miR-497 expression in the plasma could be explored as a promising novel circulating biomarker. However, to the best of our knowledge, the expression level of miR-497 has not been previously studied in retinoblastoma. The present study demonstrated that miR-497 was downregulated in retinoblastoma tissues and cell lines, and provides further evidence regarding the expression level of miR-497 in cancer.

miR-497 has been verified as a tumor suppressor in cancer. In prostate cancer, miR-497 has been demonstrated to regulate the nuclear factor $-\kappa \mathrm{B}(\mathrm{NF}-\kappa \mathrm{B})$ signaling pathway by targeting inhibitor of $N F-\kappa B$ kinase subunit $\beta$, decreasing cell growth, migration and invasion (33). In lung cancer, miR-497 inhibited cell growth by downregulation of cyclin E1 (CCNE1) (24). In ovarian cancer, upregulation of miR-497 significantly decreased angiogenesis via blockade of VEGFA (34). In human cervical carcinoma, exogenous expression of miR-497 suppressed cell proliferation, migration and invasion through downregulation of insulin-like growth factor 1 receptor (IGF-1R) and CCNE1 $(35,36)$. Furthermore, in colorectal cancer, ectopic expression of miR-497 targeted IGF-1R to suppress cell survival, growth and invasion, and to enhance cell sensitivity to apoptosis (21). The present study revealed that miR-497 inhibited cell proliferation, migration and invasion via blockade of VEGFA. Taken together, these finding indicate that miR-497 could be developed as a novel molecular marker and targeted therapy in the future. Exogenous expression of miR-497 or provision of analogous pharmaceutical compounds exogenously may be effective therapies for cancers resulting from the overexpression of miR-497's target oncogenic transcripts.

Identification of miR-497 target genes is essential for understanding its functions in retinoblastoma carcinogenesis and progression, and for exploring novel targeted therapies for retinoblastoma. In the present study, an important molecular mechanism involving miR-497 and VEGFA was demonstrated in vitro. Firstly, miRanda and TargetScan predicted that VEGFA was a potential target of miR-497. Secondly, RT-qPCR and western blot analysis revealed that miR-497 decreased VEGFA expression at the mRNA and protein levels. Finally, the Dual-Luciferase reporter assay revealed that miR-497 directly targeted the VEGFA 3'-UTR. These findings indicate that miR-497 contributed to retinoblastoma carcinogenesis and progression via directly targeting VEGFA.

VEGFA is a $35-45 \mathrm{kDa}$ heparin-binding glycoprotein and a central mediator of inflammation and angiogenesis (37). Increasing evidence has suggested that VEGFA is upregulated in numerous cancer subtypes, including retinoblastoma (38). VEGFA has been revealed to be involved in vasculogenesis, angiogenesis, cell proliferation, migration, invasion and tumor angiogenesis (39-41). A number of anti-VEGFA monoclonal antibodies that specifically bind to the VEGFA receptor to inhibit VEGFA signaling are in development at present, and certain of these antibodies are currently in clinical trials for cancer treatment (37). Therefore, regarding its cancer-associated functions, VEGFA is worthy of attention as a potential target for inhibition in retinoblastoma. The present study revealed that miR-497 inhibited proliferation, migration and invasion of retinoblastoma cells by negative regulation of VEGFA. This suggested that miR-497 could be investigated as a targeted therapy for retinoblastoma.

VEGFA has been demonstrated to be regulated by multiple miRNAs in cancer. For example, in lung cancer, miR-126 was demonstrated to suppress lung cancer cell proliferation via blockade of VEGFA (42). In hepatocellular carcinoma, miR-146a was shown to be downregulated and significantly associated with liver cancer metastasis, whereas its upregulation inhibited hepatocellular carcinoma cell invasion and metastasis by repression of VEGFA expression (43). In breast cancer, ectopic expression of miR-185 decreased cell growth and invasion and contributed to breast cancer formation by directly targeting VEGFA (44). In osteosarcoma, miR-145 and miR-410 targeted VEGFA to suppress cell growth and metastasis $(37,45)$. The present study verified that miR-497 negatively regulated the expression level of VEGFA to inhibit cell proliferation, migration and invasion in retinoblastoma. Taken together, these findings indicate that an miR-497/VEGFA-based targeted therapy may be a novel therapy for retinoblastoma.

In summary, the present study revealed that miR-497 was downregulated in retinoblastoma, and that forced expression of miR-497 significantly decreased cell proliferation, migration and invasion in retinoblastoma cells by directly targeting VEGFA. These findings indicated that miR-497 served an important role in inhibiting retinoblastoma carcinogenesis and progression by targeting VEGFA and should be investigated as a potential novel targeted therapy for retinoblastoma. 


\section{References}

1. Broaddus E, Topham A and Singh AD: Incidence of retinoblastoma in the USA: 1975-2004. Br J Ophthalmol 93: 21-23, 2009.

2. MacCarthy A, Draper GJ, Steliarova-Foucher E and Kingston JE: Retinoblastoma incidence and survival in European children (1978-1997). Report from the automated childhood cancer information system project. Eur J Cancer 42: 2092-2102, 2006.

3. Siegel RL, Miller KD and Jemal A: Cancer statistics, 2015. CA Cancer J Clin 65: 5-29, 2015

4. Beta M, Venkatesan N, Vasudevan M, Vetrivel U, Khetan V and Krishnakumar S: Identification and insilico analysis of retinoblastoma serum microRNA profile and gene targets towards prediction of novel serum biomarkers. Bioinform Biol Insights 7: 21-34, 2013.

5. Wang J, Wang X, Wu G, Hou D and Hu Q: MiR-365b-3p, down-regulated in retinoblastoma, regulates cell cycle progression and apoptosis of human retinoblastoma cells by targeting PAX6. FEBS Lett 587: 1779-1786, 2013.

6. Shields CL and Shields JA: Diagnosis and management of retinoblastoma. Cancer Control 11: 317-327, 2004.

7. Xu X, Jia R, Zhou Y, Song X, Wang J, Qian G, Ge S and Fan X: Microarray-based analysis: Identification of hypoxia-regulated microRNAs in retinoblastoma cells. Int J Oncol 38: 1385-1393, 2011.

8. Friedman DL, Himelstein B, Shields CL, Shields JA, Needle M, Miller D, Bunin GR and Meadows AT: Chemoreduction and local ophthalmic therapy for intraocular retinoblastoma. J Clin Oncol 18: 12-17, 2000.

9. Mehta M, Sethi S, Pushker N, Kashyap S, Sen S, Bajaj MS and Ghose S: Retinoblastoma. Singapore Med J 53: 128-135, 2012.

10. Shen F, Mo MH, Chen L, An S, Tan X, Fu Y, Rezaei K, Wang Z, Zhang L and Fu SW: MicroRNA-21 down-regulates Rbl expression by targeting PDCD4 in retinoblastoma. J Cancer 5: 804-812, 2014.

11. Wang J, Wang X, Li Z, Liu H and Teng Y: MicroRNA-183 suppresses retinoblastoma cell growth, invasion and migration by targeting LRP6. FEBS J 281: 1355-1365, 2014.

12. Dalgard CL, Gonzalez M, deNiro JE and O'Brien JM: Differential microRNA-34a expression and tumor suppressor function in retinoblastoma cells. Invest Ophthalmol Vis Sci 50: 4542-4551, 2009

13. Ambros V: The functions of animal microRNAs. Nature 431: 350-355, 2004.

14. Hwang HW and Mendell JT: MicroRNAs in cell proliferation, cell death, and tumorigenesis. Br J Cancer 96 (Suppl): R40-R44, 2007.

15. Calin GA, Ferracin M, Cimmino A, Di Leva G, Shimizu M, Wojcik SE, Iorio MV, Visone R, Sever NI, Fabbri M, et al: A MicroRNA signature associated with prognosis and progression in chronic lymphocytic leukemia. N Engl J Med 353: 1793-1801, 2005.

16. Sun YC, Wang J, Guo CC, Sai K, Wang J, Chen FR, Yang QY, Chen YS, Wang J, To TS, et al: MiR-181b sensitizes glioma cells to teniposide by targeting MDM2. BMC Cancer 14: 611, 2014.

17. Ventura A and Jacks T: MicroRNAs and cancer: Short RNAs go a long way. Cell 136: 586-591, 2009.

18. Finnerty JR, Wang WX, Hébert SS, Wilfred BR, Mao G and Nelson PT: The miR-15/107 group of microRNA genes: Evolutionary biology, cellular functions, and roles in human diseases. J Mol Biol 402: 491-509, 2010.

19. Livak KJ and Schmittgen TD: Analysis of relative gene expression data using real-time quantitative PCR and the 2(-Delta Delta C(T)) Method. Methods 25: 402-408, 2001

20. Harries LW: Long non-coding RNAs and human disease. Biochem Soc Trans 40: 902-906, 2012.

21. Guo ST, Jiang CC, Wang GP, Li YP, Wang CY, Guo XY Yang RH, Feng Y, Wang FH, Tseng HY, et al: MicroRNA-497 targets insulin-like growth factor 1 receptor and has a tumour suppressive role in human colorectal cancer. Oncogene 32: 1910-1920, 2013

22. Bailey-Wilson JE, Amos CI, Pinney SM, Petersen GM, de Andrade M, Wiest JS, Fain P, Schwartz AG, You M, Franklin W, et al: A major lung cancer susceptibility locus maps to chromosome 6q23-25. Am J Hum Genet 75: 460-474, 2004.

23. Tseng RC, Chang JW, Hsien FJ, Chang YH, Hsiao CF, Chen JT, Chen CY, Jou YS and Wang YC: Genomewide loss of heterozygosity and its clinical associations in non small cell lung cancer. Int J Cancer 117: 241-247, 2005.
24. Han Z, Zhang Y, Yang Q, Liu B, Wu J, Zhang Y, Yang C and Jiang Y: miR-497 and miR-34a retard lung cancer growth by co-inhibiting cyclin E1 (CCNE1). Oncotarget 6: 13149-13163, 2015.

25. Zhao X, Zhao Z, Xu W, Hou J and Du X: Down-regulation of miR-497 is associated with poor prognosis in renal cancer. Int J Clin Exp Pathol 8: 758-764, 2015.

26. Xu J, Wang T, Cao Z, Huang H, Li J, Liu W, Liu S, You L, Zhou L, Zhang $\mathrm{T}$ and Zhao Y: MiR-497 downregulation contributes to the malignancy of pancreatic cancer and associates with a poor prognosis. Oncotarget 5: 6983-6993, 2014.

27. Xie Y, Wei RR, Huang GL, Zhang MY, Yuan YF and Wang HY: Checkpoint kinase 1 is negatively regulated by miR-497 in hepatocellular carcinoma. Med Oncol 31: 844, 2014.

28. Hiroki E, Akahira J, Suzuki F, Nagase S, Ito K, Suzuki T, Sasano H and Yaegashi N: Changes in microRNA expression levels correlate with clinicopathological features and prognoses in endometrial serous adenocarcinomas. Cancer Sci 101: 241-249, 2010.

29. Chen HC, Chen GH, Chen YH, Liao WL, Liu CY, Chang KP, Chang YS and Chen SJ: MicroRNA deregulation and pathway alterations in nasopharyngeal carcinoma. Br J Cancer 100: 1002-1011, 2009.

30. Li D, Zhao Y, Liu C, Chen X, Qi Y, Jiang Y, Zou C, Zhang X, Liu S, Wang X, et al: Analysis of MiR-195 and MiR-497 expression, regulation and role in breast cancer. Clin Cancer Res 17: 1722-1730, 2011.

31. Guo J, Miao Y, Xiao B, Huan R, Jiang Z, Meng D and Wang Y: Differential expression of microRNA species in human gastric cancer versus non-tumorous tissues. J Gastroenterol Hepatol 24: 652-657, 2009.

32. Wang L, Li B, Li L and Wang T: MicroRNA-497 suppresses proliferation and induces apoptosis in prostate cancer cells. Asian Pac J Cancer Prev 14: 3499-3502, 2013.

33. Kong XJ, Duan LJ, Qian XQ, Xu D, Liu HL, Zhu YJ and Qi J: Tumor-suppressive microRNA-497 targets IKKb to regulate $\mathrm{NF}-\kappa \mathrm{B}$ signaling pathway in human prostate cancer cells. Am J Cancer Res 5: 1795-1804, 2015.

34. Wang W, Ren F, Wu Q, Jiang D, Li H and Shi H: MicroRNA-497 suppresses angiogenesis by targeting vascular endothelial growth factor A through the PI3K/AKT and MAPK/ERK pathways in ovarian cancer. Oncol Rep 32: 2127-2133, 2014

35. Han J, Huo M, Mu M, Liu J and Zhang J: miR-497 suppresses proliferation of human cervical carcinoma HeLa cells by targeting cyclin E1. Xi Bao Yu Fen Zi Mian Yi Xue Za Zhi 30: 597-600, 2014 (In Chinese)

36. Luo M, Shen D, Zhou X, Chen X and Wang W: MicroRNA-497 is a potential prognostic marker in human cervical cancer and functions as a tumor suppressor by targeting the insulin-like growth factor 1 receptor. Surgery 153: 836-847, 2013.

37. Fan L, Wu Q, Xing X, Wei Y and Shao Z: MicroRNA-145 targets vascular endothelial growth factor and inhibits invasion and metastasis of osteosarcoma cells. Acta Biochim Biophys Sin (Shanghai) 44: 407-414, 2012.

38. Youssef NS and Said AM: Immunohistochemical expression of CD117 and vascular endothelial growth factor in retinoblastoma: Possible targets of new therapies. Int J Clin Exp Pathol 7: 5725-5737, 2014

39. Zhuang Y and Wei M: Impact of vascular endothelial growth factor expression on overall survival in patients with osteosarcoma: A meta-analysis. Tumour Biol 35: 1745-1749, 2014.

40. Liu Y, Zheng Q, Wu H, Guo X, Li J and Hao S: Rapamycin increases pCREB, Bcl-2, and VEGF-A through ERK under normoxia. Acta Biochim Biophys Sin (Shanghai) 45: 259-267, 2013.

41. Wiszniak S, Mackenzie FE, Anderson P, Kabbara S, Ruhrberg C and Schwarz Q: Neural crest cell-derived VEGF promotes embryonic jaw extension. Proc Natl Acad Sci USA 112: 6086-6091, 2015.

42. Yang X, Chen BB, Zhang MH and Wang XR: MicroRNA-126 inhibits the proliferation of lung cancer cell line A549. Asian Pac J Trop Med 8: 239-242, 2015.

43. Zhang Z, Zhang Y, Sun XX, Ma X and Chen ZN: microRNA-146a inhibits cancer metastasis by downregulating VEGF through dual pathways in hepatocellular carcinoma. Mol Cancer 14: 5 , 2015.

44. Wang R, Tian S, Wang HB, Chu DP, Cao JL, Xia HF and Ma X: MiR-185 is involved in human breast carcinogenesis by targeting Vegfa. FEBS Lett 588: 4438-4447, 2014.

45. Zhao D, Jia P, Wang W and Zhang G: VEGF-mediated suppression of cell proliferation and invasion by miR-410 in osteosarcoma. Mol Cell Biochem 400: 87-95, 2015. 